\title{
Benefícios da Utilização de Protótipos de Baixa Fidelidade no Desenvolvimento de Jogos
}

\author{
Benefits of the Utilization of Low-Fidelity Prototypes on Game Development
}

\author{
João Gabriel Guedes Pinheiro \\ Universidade do Vale do Itajaí, Brasil \\ joaogabrielpinheiro@gmail.com
}

\begin{abstract}
This paper attempt to bring some of the benefits obtained by the use of low fidelity prototypes in game development. These benefits were observed through the analysis of the development of six games developed in academic environment. However, with the limitations related to the size of the development team, and the project scope, some of the results obtained in this paper should not be adopted in every situation. There is, however, benefits described in this paper that can be observed in game development, regardless of its scope.
\end{abstract}

Keywords: Prototypes, Games, Development

\section{Introdução}

Este trabalho tem como objetivo demonstrar, por meio de estudos de casos, os benefícios da utilização de protótipos de baixa fidelidade no desenvolvimento de jogos analógicos e digitais desenvolvidos em ambiente acadêmico. Este artigo foi elaborado a partir da coleta de referencial bibliográfico relacionado à área de design de jogos, e com base nele foram elaborados jogos digitais e também um jogo analógico. Adotando estes jogos como estudos de caso, este artigo relata os benefícios obtidos pelo uso de protótipos de baixa fidelidade no desenvolvimento de jogos, comparando alguns dos métodos utilizados pelas equipes com métodos propostos por outros autores, e demonstra por meio dos resultados obtidos, críticas e comentários para futuros desenvolvedores a cerca dos métodos adotados.

\section{Metodologia de Pesquisa}

Para a coleta de referencial bibliográfico, foi utilizado o método proposto por Lakatos e Marconi (2003), com critérios qualitativos: foram utilizados apenas autores que demonstram claramente suas ideias e conceitos. Com estes critérios, a pesquisa teve fins exploratórios, com o objetivo de identificar conceitos e métodos que podem ser utilizados no design de jogos. Foram utilizados como fontes bibliográficas livros e artigos relacionados à área de jogos.
Para a elaboração deste trabalho, em conjunto com as referências obtidas, também foi utilizado o estudo dos jogos desenvolvidos em ambiente acadêmico, de diferentes gêneros, com o foco na identificação dos pontos positivos e negativos decorrentes da aplicação de protótipos durante o desenvolvimento de cada jogo.

\section{Referencial Teórico}

Para o desenvolvimento deste trabalho, houve a divisão do referencial teórico em material relacionado ao design do jogo, material referente à produção estética e por fim, material referente a protótipos de baixa fidelidade.

Entre os autores selecionados, Novak (2010), Schell (2011) e Schuytema (2008) foram utilizados no desenvolvimento dos jogos demonstrados no estudo de caso, enquanto o restante do referencial, como Dondis (1997) e Sousa (2010) foram adotados como critérios de análise dos resultados obtidos, sendo que estes autores foram utilizados como forma de se analisar os resultados obtidos pelos artistas responsáveis.

Novak (2010) foi adotada por trazer a metodologia utilizada como base para os jogos desenvolvidos, por ser de fácil entendimento e utilização, pertinente ao desenvolvimento de jogos analógicos e também ao desenvolvimento de jogos digitais. Porém, devido ao foco do artigo, este estudo tem como princípio as etapas de pré-produção e prototipação, enquanto a conceituação, produção e pós-produção não receberão 
ênfase neste trabalho.

Schell (2011) e Schuytema (2008) foram adotados como requisitos de design. Schell (2011) por trazer as lentes do game design, uma lista de perguntas que o game designer deve se fazer, referentes à todo o processo, e Schuytema (2008) por trazer os átomos do design de jogos, uma lista de perguntas relacionadas ao design do jogo em si.

\section{Uso de Protótipos em um Jogo Analógico}

Esta seção do artigo se refere à aplicação de protótipos de baixa fidelidade no desenvolvimento de um jogo analógico, com mecânicas de gerenciamento de recursos e montagem de equipes.

Este jogo analógico foi desenvolvido como um trabalho de conclusão de curso, graduação interdisciplinar, com uma equipe composta por um game designer e um artista gráfico, durante um ano. Foi feita a determinação pela equipe que seria um jogo analógico, sem o uso de componentes digitais, com foco em satisfazer o público que gosta de animações japonesas.

\section{Desenvolvimento do Jogo Analógico}

O jogo foi desenvolvido utilizando o método de Novak (2010), com as etapas de conceituação, pré-produção, prototipação, produção e pós-produção. Estas etapas foram adotadas como referência por serem pertinentes ao desenvolvimento de jogos de tabuleiro. Como forma de complementar o processo, foi adotado o método de Chandler (2012), com o uso de diversos ciclos de produção, testes e avaliação dos resultados obtidos.

Mahoney (2001) define um jogo como algo que é composto pelos elementos de uma estrutura, onde ações são realizadas para atingir certo objetivo. Esta classificação, embora válida, não separa os jogos analógicos dos jogos digitais. Neste caso, uma definição como a proposta por Crifmer (2011), suporta outras definições sobre o que é um jogo, por se aprofundar em características específicas dos jogos analógicos, como tabuleiros, cartas, dados e outras peças.

Esta definição de Crifmer (2011) demonstra as vantagens de se utilizar protótipos de baixa fidelidade no desenvolvimento de jogos analógicos: a equipe pode testar o jogo com estes protótipos, usando materiais como papel, ou usando programas como o Microsoft Paint e simuladores de dados online para simular os dados, se necessários. No caso de protótipos que possuam uma versão tátil, como papel, a experiência será próxima daquela a que o usuário terá acesso, com papel, dados e outras peças.

Sobre os jogos analógicos, a equipe ainda pode adotar matrizes de validação, como as propostas por Baxter (2000) junto à sugestões de design propostas por Schell (2011) e Schuytema (2008). No desenvolvimento do jogo, os átomos de Schuytema (2008) foram considerados de maior importância, e os testes iniciais focaram em elementos como os objetivos claros, a presença de vitórias aninhadas e as falhas terem um custo.
Neste projeto, foram estes os três átomos de maior importância: os objetivos claros pelo jogo ser complexo, com diferentes tipos de regras e funções. Este átomo foi avaliado com base no manual do jogo. Neste tipo de situação, equipes podem testar o manual, utilizando parte do público alvo, para avaliar se o mesmo é de fácil entendimento pelos meios que julgarem mais eficiente, como questionários ou entrevistas. O segundo átomo foi as vitórias aninhadas: foram utilizadas para reduzir a monotonia no jogo, pois há apenas uma vitória no final. Por meio dos testes com os protótipos, foi possível acompanhar os jogadores, identificando os momentos mais prazerosos e também os mais monótonos, com o objetivo de aumentar o divertimento e a imersão do jogador no jogo. Por fim, o terceiro átomo: as falhas terem um custo se referem ao universo do jogo, como na produção de animações japonesas: o jogador deve ser responsável pelas suas ações, e estas devem ter custos que façam com que ele sempre pense se os benefícios podem superar os eventuais riscos.

Estes testes, mesmo tendo sido realizados sem preocupação visual, sem as ilustrações das cartas finalizadas, possibilitaram identificar problemas nas mecânicas do jogo, que foram sendo corrigidas durante o jogo, sem interrupções. Foram realizados também outros testes, com cartas em branco, sem nenhum tipo de detalhe ou acabamento visual, que assim como os primeiros testes, também apresentaram problemas. Entre estes problemas que puderam ser identificados nestes primeiros protótipos, estavam a pontuação do jogo, um sistema muito complexo, e que forçava os jogadores a pararem para calculá-la, a classificação de personagens, que não deixava claro quais eram obrigatórios e quais não o eram, e a clareza do manual, que possuía lacunas que prejudicavam o entendimento do jogador.

A equipe priorizou a produção estética apenas no final do processo, quando as mecânicas já estavam validadas e as necessidades dos jogadores definidas. Assim, evitou-se o problema de ser desenvolvido um modelo de carta e, depois, ela ser excluída por não se enquadrar no restante do jogo, $p$ que geraria atrasos na produção.

Deste projeto, uma conclusão obtida foi que jogos analógicos podem ser testados cedo, pois o jogador utilizará os mesmos meios de interação que a equipe utiliza nos testes com protótipos de baixa fidelidade. Outra conclusão é que testes de baixa fidelidade para jogos analógicos apresentam baixo custo para serem produzidos: não é necessário qualquer produção estética, e podem ser realizados apenas com uma simples impressão da documentação e o recorte do que for necessário para simular as cartas ou peças do jogo.

É importante realçar que, para o desenvolvimento de jogos de tabuleiro, não há quaisquer problemas que equipes de desenvolvedores possam enfrentar em relação ao uso de protótipos de baixa fidelidade. Utilizando o método de Novak (2010), a equipe pode iniciar os testes durante a etapa de pré-produção, em paralelo com a construção dos documentos de design. 


\section{Uso de Protótipos em Jogos Digitais}

Esta seção do artigo se refere à aplicação de protótipos debaixa fidelidade no desenvolvimento de cinco diferentes jogos digitais. Em cada subseção, haverá a descrição das diferentes etapas onde foram aplicados os protótipos de baixa fidelidade, seguindo o método proposto por Novak (2010), como os protótipos foram aplicados e quais benefícios a utilização destes protótipos trouxeram ao desenvolvimento do projeto.

\section{Protótipo de jogo de ação sidescroller}

Este projeto tinha como objetivo representar como funciona o jogo proposto, onde um jogador assumia o papel de quatro personagens, que deveriam vencer seus inimigos em um mundo bi-dimensional, com elementos do cenário destrutíveis e diferentes tipos de inteligência artificial para os inimigos.

A equipe deste projeto era composta por um game designer, um programador e um artista gráfico. Porém, devido ao escopo do projeto, decidiu-se que o foco do trabalho deveria ser numa fase do jogo funcional, e, se possível, a inclusão das animações no jogo.

No primeiro momento, após o desenvolvimento da documentação, a equipe preparou protótipos de papel como forma de avaliação do fluxo das telas. Devido ao ambiente de trabalho, e às necessidades do projeto, foi utilizado o computador como forma de realizar estes testes.

Em jogos digitais, onde a interface não sofrerá alterações, como a posição de botões que controlam o fluxo do jogo, o uso de ferramentas como o Adobe Photoshop permite, com o uso de camadas, o teste do fluxo de telas, com a vantagem, em relação à realização deste tipo de testes em papel, de já ser uma forma de interação similar à usada no jogo final, que utiliza o mouse e o teclado.

Entretanto, para a avaliação do jogo em relação às suas mecânicas, não foi possível testá-lo em protótipos de papel. Ainda que Camilo (2013) descreva algumas soluções para questões como mecânicas de salto ou movimento, este tipo de teste não traz a fluidez do jogo digital. Neste projeto, em específico, um dos elementos do jogo era ser rápido e fluido, de maneira que as ações necessitavam de respostas imediatas, características que um protótipo de papel não é capaz de trazer.

Para a produção do jogo, foi adotado o uso da ferramenta Stencyl. Este programa possibilitou aos desenvolvedores produzir um jogo sem utilizar linhas de código, através da programação em bloco, mais fácil e simples de usar para aqueles sem experiência em programação, sendo mais visual, que permitiu aos desenvolvedores se focarem na lógica, e não na transformação desta lógica em linhas de código. Com o uso desta ferramenta, o game designer e o programador foram capazes de desenvolver o protótipo.

Durante o desenvolvimento deste projeto, houve duas grandes conclusões: a primeira conclusão é que cabe à equipe determinar como realizar seus testes relacionados ao fluxo de telas. Embora seja possível testá-lo com protótipos em papel, a equipe pode optar por realizar estes testes em computador, e obter um feedback mais próximo do real, se este protótipo já utiliza fontes e formas, por exemplo, como as que serão utilizadas no produto final

A segunda conclusão é que, em casos onde não seja possível testar o jogo utilizando protótipos em papel, a equipe pode adotar ferramentas que facilitem a produção de um protótipo funcional. Assim, mesmo que a equipe não possua programadores capazes, ainda pode demonstrar o conceito do jogo que está sendo produzido.

\section{Projeto de jogo estilo Bejeweled}

Este projeto tinha como objetivo desenvolver um advergame para algum tipo de comércio definido pela equipe. Após votação, ficou determinado que o projeto seria utilizado como forma de atender as necessidades de uma joalheria. Para investigação do que consiste um advergame, foi utilizado Medeiros (2009).

Com o objetivo definido, foi iniciado o processo de brainstorm,e a equipe, composta por dois programadores, um game designer e um artista gráfico, decidiu que o jogo seguiria o modelo do jogo Bejeweled, onde um jogador deve formar combinação de três ou mais peças da mesma cor.

Para este jogo, o fluxo de telas foi testado com protótipos em papel, e foi determinado pelos professores responsáveis que o jogo também deveria ser testado de maneira analógica.

Embora um jogo deste estilo possa ser testado dessa forma mais facilmente que um jogo de ação, há problemas que prejudicam a avaliação do mesmo pela equipe. Como escrito na análise do protótipo de jogo sidescroller, os protótipos de jogos digitais possuem dificuldades para representar a fluidez deste tipo de jogo. Ainda que um jogo estilo Bejeweled não tenha a necessidade de ser rápido, pois a interação com o jogador é mínima, e não é a diferença entre o jogador ganhar ou perder o jogo, há a questão de como representar ao mesmo tempo o fato de que as peças devem parecer aleatórias sendo que, ao mesmo tempo, deve permitir movimentos para o jogador e não possuir nenhuma combinação de três ou mais jóias já existentes. Este último problema, principalmente, é importante por entregar pontos para o jogador, sem ele ter trabalhado por eles.

A equipe pode adotar soluções para alguns destes problemas. Se o jogo é, de fato, aleatório, pode-se utilizar algum tipo de ferramenta que permita o sorteio de números, correspondentes às peças do jogo, para a distribuição delas no cenário. Porém, se esta for a solução adotada, há o risco de se formar combinações antes da influência do jogador, e além do trabalho de se preparar o jogo, a cada movimento a equipe deve re-sortear as peças, impedindo que o jogo funcione de maneira fluida.

A solução adotada para o desenvolvimento do projeto foi ignorar quaisquer outras condições exceto a aleatoriedade. As peças foram colocadas no tabuleiro sem nenhuma preocupação, e se houvesse quaisquer tipos de combinação elas seriam pontuadas normalmente. Foi possível testar o jogo, 
porém a experiência do jogador não foi representada com fidelidade. Não houve nenhuma garantia de que o teste de fato demonstrou o funcionamento de um jogo onde as peças parecessem aleatórias, mas que permitissem movimentos do jogador e que não iniciasse com combinações já existentes no tabuleiro.

A principal conclusão, obtida neste trabalho, é que em determinadas situações, os desenvolvedores podem realizar testes utilizando protótipos de baixa fidelidade em jogos digitais, e a experiência será similar ao que é proposto. Porém, haverá elementos que não poderão ser analisados corretamente. Nestes casos, cabe à equipe determinar o que será mais proveitoso com os recursos que possuem: trabalhar com o uso de protótipos de baixa fidelidade, e correr o risco de a experiência do usuário não corresponder à aquela dos testes, ou desenvolver protótipos digitais e ter a experiência real do usuário.

\section{Projeto de jogo de Newsgame}

Este projeto tinha como objetivo desenvolver um newsgame baseado em uma notícia do site da universidade. Num primeiro momento, assim como no desenvolvimento do advergame, foi realizada uma pesquisa para identificar o que é um newsgame, tendo sido utilizado como base Mazotte (2013), que comenta o processo de desenvolvimento, a diferença entre um newsgame e um jogo "comum", e suas primeiras aplicações comerciais.

A equipe foi composta por um programador, um game designer e um artista gráfico. Tentou-se uma comunicação com os responsáveis pela notícia, como forma de proporcionar maior veridicidade ao jogo, porém não foi possível este contato.

A notícia, referente a uma nova tecnologia de câmeras que detecta motoristas sem o cinto de segurança e os multam, deu origem a um jogo onde carros viriam em direção ao jogador, que deve identificar os motoristas sem o cinto de segurança.

Assim como os demais jogos, o jogo foi inicialmente testado com protótipos em papel para a avaliação do fluxo de telas, e quando resultados satisfatórios foram obtidos, foi iniciado o processo de testes com protótipos jogáveis. Também foram utilizados desenhos em papel para se ter ideia de como funciona a câmera do jogo, entre as propostas por Rogers (2010). Após análise da equipe, foi adotada uma união entre a câmera estática e a câmera em primeira pessoa.Ao contrário dos jogos citados anteriormente, não houve testes utilizando protótipos de papel com o objetivo de se analisar o funcionamento deste jogo, pela dificuldade de simular a experiência usando este tipo de material. Neste tipo de situação, cabe à equipe determinar como serão feitos os testes.

Durante o desenvolvimento do protótipo do jogo sidescroller, foi adotado o uso da Stencyl como forma de desenvolver o protótipo jogável. Entretanto, neste projeto, o programador já possuía conhecimentos de programação para desenvolver o jogo utilizando ferramentas mais adequadas. Cabe à equipe, então, determinar o que será mais eficaz ao longo prazo. É possível, com o uso de ferramentas, que o game designer desenvolva os protótipos jogáveis, porém há situações onde o programador também estará desenvolvendo o jogo para ser entregue, e o desenvolvimento de um protótipo em simultâneo ao jogo final pode prejudicar a progressão do trabalho.

A equipe deve avaliar os custos e os benefícios de se desenvolver protótipos jogáveis. Também deve determinar com o programador responsável se devem entregar protótipos feitos com o que já foi realizado da programação do jogo, seguindo processos do design iterativo, correndo riscos de a preocupação com estas entregas atrasarem o processo, ou a equipe desenvolver, sem o apoio do programador, um protótipo para ser avaliado e entregue, se necessário. Nestes casos, onde a equipe desenvolve um protótipo em paralelo, deve-se pensar se este desenvolvimento irá trazer vantagens a longo prazo, e se estes protótipos poderão ser utilizados futuramente, ou se serão usados apenas para demonstrar o conceito.

\section{Projeto de jogo estilo Launcher}

Este projeto tinha como objetivo o desenvolvimento de um jogo com temática que remetesse às olimpíadas de inverno. No caso, a equipe composta por dois programadores, um game designer e um artista gráfico, através do uso do brainstorm, modificou o conceito de esqui, e desenvolveu um jogo com a temática steampunk.

Por ser um jogo maior que os descritos anteriormente, não foram utilizados protótipos de papel para o fluxo de telas. Foram adotados em seu lugar conceitos do design iterativo, como proposto por Nielsen (1993). Com o uso destes conceitos, a equipe pode desenvolver as mecânicas de uma loja dentro do jogo, assim como as outras mecânicas. Para análise dos resultados foram realizadas reuniões semanais.

A vantagem de ter utilizado o design iterativo, como dito, foi o aproveitamento do tempo. Devido ao escopo, o maior entre os jogos citados até agora, e a própria natureza de um jogo estilo launcher, usualmente com cenários largos e altos, diferentemente de jogos sidescrollers, aos programadores foi possível desenvolver o jogo aos poucos, usando imagens simples, como quadrados e círculos, para representar as ilustrações que ainda não haviam sido produzidas, não tendo a necessidade de o artista responsável terminar seu trabalho para então ser iniciado o desenvolvimento dos protótipos.

Assim como no exemplo anterior, a equipe de desenvolvedores deve se perguntar o que será mais proveitoso para o projeto. Porém, em casos similares, onde o jogo requer maior trabalho de todos os envolvidos, como a necessidade de maior documentação, maior quantidade de código para ser programado, ou maior quantidade de ilustrações, a utilização do design iterativo para o desenvolvimento dos protótipos é fundamental. Ele permite o acompanhamento constante da produção, assim qualquer problema, fosse ele em ilustrações, erros no jogo ou no design puderam ser corrigidos assim que encontrados, não havendo a necessidade de se desenvolver builds jogáveis para, então, serem encontrados erros. 
Um segundo benefício foi ter protótipos mais rápidos e próximos da versão final do jogo, justificado pelo uso da programação, e de se utilizar imagens simples como forma de avaliação. E por utilizar o próprio jogo como protótipo, a equipe não gastou recursos desenvolvendo um protótipo que seria utilizado apenas para validar as mecânicas e conceitos do jogo.

\section{Projeto de jogo utilizando o Oculus Rift}

Este projeto tinha como objetivo desenvolver um jogo que utilizasse, de alguma maneira, o Oculus Rift, e que também tratasse de um tema determinado. A equipe, composta por um game designer, dois artistas gráficos, e um programador sem experiência, desenvolveu o conceito de um jogo bidimensional, com ênfase na furtividade.

Este projeto não foi concluído por falhas no escopo e nas técnicas utilizadas. Conforme escrito anteriormente, havia neste trabalho um programador que não tinha experiência no uso da engine escolhida, no caso a Unreal Engine.

Este é um ponto importante no desenvolvimento de protótipos, e também de jogos: o programador deve escolher uma engine que seja capaz de suportar o estilo de jogo escolhido, porém a equipe também deve ter conhecimento sobre a mesma, para, se necessário, poder desenvolver protótipos por conta própria.

A engine adotada era capaz de suportar o projeto de jogo, porém houve um erro no design, que não considerou a imersão, usando o Oculus Rift. O design do jogo foi refeito, e com estas alterações, o projeto mudou de características, abandonando o conceito de uma aventura em um universo em duas dimensões para um jogo tridimensional, com ênfase na ação e na furtividade.

Pela falta de experiência da equipe em relação à engine, foi feito um protótipo jogável para testar as mecânicas do jogo, com o fluxo de telas já funcional, assim como a transição de mundos. Entretanto, não havia neste protótipo personagens inimigos, não sendo possível avaliar a interação com o jogo, sendo impossível, assim, garantir que o mesmo estava balanceado, que estava divertido e que as mecânicas funcionavam como previsto.

Caso outro membro da equipe conseguisse utilizar uma engine diferente, e tivesse tempo e condições para o desenvolvimento de um protótipo, ele poderia ser desenvolvido em separado, mas não havia ninguém neste projeto com habilidade suficiente para o desenvolvimento de um.

Este foi o ponto principal por este jogo não ter sido completado: o programador adotou uma engine que foi capaz de suportar o estilo de jogo, mas que não tinha documentação o suficiente, na internet, para sanar algumas de suas dúvidas. Porém, há outras engines, como a Unity, que também são capazes de suportar o estilo de jogo, ainda que com pequenas restrições, e que possuem maior quantidade de documentação disponível.

Outro problema foi a tecnologia do Oculus Rift, pois não foi possível obter informações de como unir o Oculus Rift à Unreal. Novamente, foi uma questão fundamental, considerando a obrigatoriedade de se utilizar o Oculus Rift no jogo, e nenhum dos membros da equipe ter conhecimento de sua aplicação.

Deste projeto, pode-se destacar uma conclusão: dependendo do escopo do projeto, a equipe deve se perguntar se as ferramentas utilizadas para o desenvolvimento são as que melhor satisfazem as necessidades do seu projeto e, ainda que estas ferramentas sejam as mais bem aceitas pela indústria, deve se perguntar se os responsáveis pelo desenvolvimento deste projeto possuem a habilidade necessária para utilizálas, e cumprir com suas respectivas funções dentro do desenvolvimento de um jogo.

O escopo do projeto é fundamental: a equipe deve ter consciência de quando seu escopo está além de suas capacidades e ser capaz de identificar o que deve ser removido para que seja possível entregar o jogo no prazo determinado. No presente caso, foram eliminadas todas as mecânicas relacionadas à furtividade, foram comprados modelos tridimensionais de personagens, armas e de elementos do cenário, porém a equipe não foi capaz de desenvolver o projeto.

\section{Discussões Gerais}

As conclusões obtidas neste trabalho não são pertinentes a todos os casos de desenvolvimento de jogos, sejam eles analógicos ou digitais. Porém, há uma conclusão que pode ser observada em todos estes projetos: a prototipação é uma parte fundamental do processo de desenvolvimento, e é necessária a total interação entre a equipe; todos os envolvidos no processo de desenvolvimento devem ter o conhecimento dos protótipos e serem capazes de identificar o que funcionou ou não, para correções futuras.

No jogo analógico, os benefícios de se utilizar protótipos de baixa fidelidade são claros: o designer pode, com poucos recursos, desenvolver um protótipo funcional do jogo, com a certeza de que a experiência do jogo, no protótipo, será a mesma experiência que o jogador terá com o jogo finalizado. Pode ser que, por escolha da equipe, estes testes não possuam todas as ilustrações finalizadas, porém ainda assim o jogo pode ser testado.

Em relação aos jogos digitais também há benefícios no uso de protótipos. Porém, ao contrário do jogo analógico, onde aqueles podem ser feitos com papel, com o jogo digital há situações onde eles não são o suficiente para analisar e validar o jogo. Testes relacionados a interface, ou ao estilo de câmera, como as descritas em Rogers (2010), podem ser testados em papel. Porém, se o objetivo da equipe é avaliar o funcionamento do jogo, apenas em alguns casos, onde a fluidez não é essencial a ele, protótipos de papel podem ser aplicados.

Quando o uso de protótipos de papel não sejam o suficiente, cabe a equipe determinar como serão feitos os protótipos jogáveis de seus jogos. Uma opção é o uso de ferramentas que facilitem a programação do jogo, mesmo em 
equipes sem programadores. Porém, neste caso, a equipe pode ficar limitada pela ferramenta, um problema que não existirá caso os protótipos sejam desenvolvidos em uma engine. Neste caso cabe aos programadores a tarefa do desenvolvimento.

O uso de uma engine para a programação do jogo não significa, entretanto, que uma ferramenta como a Stencyl não possa ser utilizada. $\mathrm{O}$ uso de uma engine em conjunto com o design iterativo permite um processo mais eficaz, pois os protótipos já são utilizados como a base do jogo. Porém, caso haja complicações com a programação, nesta situação, a equipe não será capaz de ter um protótipo jogável.

O mais importante, no desenvolvimento de jogos, em conjunto com os protótipos, é a definição do escopo. Em equipes pequenas, apenas os protótipos já servem para demonstrar se o escopo está muito além das capacidades da equipe. Nestes casos, cabe a ela decidir o que pode ser excluído do jogo, para ter condições de lançá-lo.

\section{Sobre a Aplicação e Avaliação de Protótipos}

Neste trabalho, foram observadas conclusões sobre a aplicação de protótipos de baixa fidelidade em jogos já desenvolvidos, onde já haviam sido obtidos os resultados, e que por serem trabalhos acadêmicos, possuíam uma série de critérios que podem não ser encontrados na indústria.

Além das considerações citadas na seção anterior, é fundamental para o desenvolvimento de qualquer jogo a aplicação de protótipos, assim como a seleção de ferramentas e técnicas. Apenas com o uso de protótipos o jogo pode ser avaliado: toda a documentação pode estar sem falhas, e todas as ações possuírem a reação prevista, mas apenas com o protótipo a equipe pode, de fato, confirmar ou não que o jogo funciona como planejado.

Para o desenvolvimento destes protótipos, os utilizados nestes projetos seguiram o design iterativo, iniciando o desenvolvimento pelas atividades que requeriam menos trabalho, como fluxo de telas e interface, para aquelas mais trabalhosas, como o funcionamento do jogo.

Algumas das lentes de Schell (2011) podem ser utilizadas ainda antes da prototipação do jogo, como a lente da inspiração infinita, os oito filtros, atenuação de riscos, habilidade, equidade e desafio: se referem ao conceito do jogo, porém devem ser aplicadas para a equipe validar seu projeto: um jogo que possua muitos riscos, e não é original, ou venderá pouco (o que deve ser repensado) ou ainda cancelado.

Se a equipe decidir realizar diferentes protótipos, ela pode separar este processo em diferentes etapas, como uma série de protótipos para análise da interface, uma série para análise do fluxo de telas, e por fim uma série para o funcionamento do jogo. A equipe pode assim analisar cada elemento em separado, com métodos de análise específicos para cada situação. Uma desvantagem deste método, porém, é que não haverá uma análise do jogo seguindo a lente do design holográfico, referente ao contexto geral do jogo.
$\mathrm{Na}$ análise da interface, lentes como elegância e personalidade podem ser usadas para validar a proposta. Embora estas lentes não tragam critérios relacionados à estética, pode-se utilizar autores como Dondis (1997) e Sousa (2010) para o desenvolvimento desta parte do projeto.

$\mathrm{Na}$ interface, autores como Rogers (2010) podem ser utilizados para complementar as necessárias avaliações, por descrever diferentes tipos de câmera, diferentes tipos de HUD - head-up display -, e ainda trazerem questões aplicáveis ao funcionamento do jogo, como mapas, design dos inimigos, assim como suas localizações, e os combates envolvidos.

$\mathrm{Na}$ análise do jogo, pode-se adotar algumas das lentes de Schell (2011): a experiência essencial, que deve ser uma das principais em um jogo, considerando que se refere à experiência que o jogador terá. Entre outras lentes, como a diversão, o fluxo, a unificação, ressonância e balanceamento: a avaliação delas pode ser subjetiva, como diversão, ou o fluxo, por isso é fundamental que sejam realizados testes com o público, ou pessoas não relacionadas ao projeto, para que estes conceitos possam ser analisados.

Lentes como o espaço funcional, ação, objetivo e regras também podem ser observadas nos protótipos de jogos: com um protótipo funcional, a equipe pode avaliar o jogo e identificar problemas e oportunidades com suas ações, e a clareza de seus objetivos e regras.

\section{Conclusão}

Este trabalho surgiu pela análise do desenvolvimento de jogos feitos em ambiente acadêmico, e com equipes de duas até cinco pessoas. Houve, para o desenvolvimento destes jogos, uma pesquisa bibliográfica com o objetivo de identificar as suas principais características, e para o desenvolvimento deste artigo, a análise do desenvolvimento de cada jogo, como estudos de caso, usando as observações do game designer, junto aos cronogramas utilizados nos projetos.

Os resultados deste trabalho são relacionados ao uso de protótipos de baixa fidelidade no desenvolvimento de jogos. Para o jogo analógico, o baixo custo da produção dos protótipos, e a certeza de que a experiência do jogador estará fielmente representada, permitem aos desenvolvedores terem uma ideia real de como será o jogo, sem ser necessário pensálo ou desenvolvê-lo por completo.

Em relação aos jogos digitais há mais características que devem ser citadas. Por exemplo, o uso de protótipos de papel, para análise da interface, aliado ao uso de protótipos digitais, podem ser utilizados para validação das mecânicas e interface. A equipe pode, ainda, utilizar o próprio jogo como protótipo, em fase de produção, como forma de validar e demonstrar seu conceito. Uma terceira característica do protótipo do jogo digital é que permite uma análise do escopo do projeto: se o protótipo está além da capacidade da equipe, o jogo final também estará, e este escopo deve ser repensado para se adequar ao que a equipe pode produzir. 


\section{Agradecimentos}

O autor agradece professores, familiares e colegas que colaboraram com o desenvolvimento deste artigo.

\section{Referencias}

Baxter, M. (2000). Projeto de Produto: Guia prático para o design de novos produtos $2^{a}$ Edição. São Paulo: Blucher.

Camilo, J. (14 de Agosto de 2013). Low-Fidelity Prototype. Acesso em 29 de Julho de 2015, disponível em The Legend of Johnny: http://thelegendofjohnny.com/tutorials/lowfidelity-prototype

Chandler, H. M. (2012). Manual de Produção de Jogos Digitais. Porto Alegre: Bookman.

Crifmer. (04 de Maio de 2011). Board Game Design: Elements of a Game. Acesso em 01 de Agosto de 2015, disponível em Hub Pages: http://crifmer.hubpages.com/hub/Board-GameDesign-Elements-of-a-Game

Dondis, D. A. (1997). Sintaxe da Linguagem Visual $2^{\mathrm{a}}$ Edição. São Paulo: Martins Fontes.

Khoo, C. (05 de Maio de 2012). Play testing a game design the low fidelity way. Acesso em 29 de Julho de 2015, disponível em Gamasutra: http://www.gamasutra.com/blogs/ ChrisKhoo/20120525/171131/Play_testing_a_game_design_ the_low_fidelity_way.php

Lakatos, E. M., \& Marconi, M. d. (2003). Fundamentos da Metodologia Científica 5a Edição. São Paulo: Atlas.
Maroney, K. (Maio de 2001). My Entire Waking Life. Acesso em 01 de Agosto de 2015, disponível em The Games Journal: http:// www.thegamesjournal.com/articles/MyEntireWakingLife. shtml

Mazotte, N. (08 de Agosto de 2013). Spanning the line between journalism and entertainment, newsgames growing in Brazil. Acesso em 03 de Agosto de 2015, disponível em Journalism in the Americas Blog: https://knightcenter.utexas.edu/ blog/00-14254-spanning-line-between-journalism-andentertainment-newsgame-growing-brazil

Medeiros, J. F. (8-10 de Outubro de 2009). Advergames: A publicidade em jogos digitais como forma de atrair o consumidor.VIIISimpósio Brasileirode Jogose Entretenimento Digital .

Nielsen, J. (Novembro de 1993). Iterative User Interface Design. IEEE Computer , pp. 32-41.

Novak, J. (2010). Desenvolvimento de Games. São Paulo: Cengage Learning.

Rogers, S. (2010). Level Up! The guide to great video game design. Chichester: John Wiley \& Sons.

Schell, J. (2011). A arte de game design: O livro original. Rio de Janeiro: Elsevier.

Schuytema, P. (2008). Design de games: Uma abordagem prática. São Paulo: Cengage Learning.

Sousa, R. P. (30 de Novembro de 2010). Gramática Comparada da Representação Gráfica. Convergências , pp. 1-10. 